\title{
Organic Phosphates Analyzer Using High-Performance Anion-Exchange Chromatography and a Postcolumn Phosphomolybdic Acid Reaction
}

\author{
Yoshihiko Ikeguchi, Hiroshi Nakamura ${ }^{\dagger}$ and Terumi Nakajima \\ Department of Analytical Chemistry, Faculty of Pharmaceutical Sciences, The University of Tokyo, \\ Hongo, Tokyo 113, Japan
}

\begin{abstract}
An organic phosphates analyzer was developed based on high-performance anion-exchange chromatography and a postcolumn phosphomolybdic acid reaction. The organic phosphates were separated on an Asahipak NH2P-50 column and then introduced into a postcolumn reaction detector in which organic phosphates were heated at $170^{\circ} \mathrm{C}$ in $2.0 \mathrm{M}$ sulfuric acid for $5.8 \mathrm{~min}$. The resultant orthophosphate was monitored at $830 \mathrm{~nm}$ after a selective reaction with a molybdenum reagent. When $1.0 \mathrm{nmol}$ of each sugar phosphate solution was employed (injection volumn, $10 \mu \mathrm{l}$ ) the relative standard deviations were $1.9-2.6 \%(n=8)$. The detection limits $(S / N=3)$ of the organic phosphates were $c a$. 100 pmol as the injected amount.
\end{abstract}

Keywords Organic phosphate, phospho-amino acid, sugar phosphate, high-performance anion-exchange chromatography, on-line acid hydrolysis, phosphomolybdic acid reaction, heteropoly blue complex

Several methods have been reported for the detection and determination of organic phosphates. Baba $e t$ al. ${ }^{1}$ have reported on a flow injection analysis (FIA) method for nucleotides involving the hydrolysis of nucleotides in $0.53 \mathrm{M}$ sulfuric acid and successive conversion of the resultant orthophosphate to the so-called heteropoly blue complex with a molybdenum reagent. Baba et al. ${ }^{2}$ also developed a coupled high-performance liquid chromatography (HPLC) and FIA system for the separation and detection of nucleoside $\mathrm{H}$-phosphonates. Recently, we reported on the FIA method ${ }^{3}$, which enables the determination of various organic phosphates by a phosphomolybdic acid reaction following quantitative hydrolysis. On the other hand, ${ }^{32} \mathrm{P}$-labeled phospholylated peptides, which are the final products in protein kinase assays, have been measured based on their radioactivity counts. ${ }^{4-7}$ Although a selective separation of nucleosides ${ }^{8}$ and organic posphates ${ }^{8}$ was achieved on a titania column, no analytical method that is selective to organic phosphates is available, despite their importance in bioscience. In this study, therefore, the development of an organic phosphates analyzer was attempted by combining the FIA method ${ }^{3}$ as the postcolumn detection system with the anion-exchange HPLC of organic phosphates.

\footnotetext{
$\dagger$ To whom correspondence should be addressed.

T.N. Present address: Suntory Institute for Bioorganic Research, 1-1-1, Wakayamadai, Shimamoto, Mishima, Osaka 618, Japan
}

\section{Experimental}

\section{Materials and reagent}

Adenosine 5'-monophosphate sodium salt (AMP), adenosine 5'-triphosphate disodium salt (ATP), $O$ phospho-DL-serine (P-Ser), $O$-phospho-L-threonine (PThr), $O$-phospho-DL-tyrosine (P-Tyr) and D-fructose 6phosphate disodium salt (Fru-6-P) were purchased from Sigma (St. Louis, MO, USA). Glucose 1-phosphate dipotassium salt (Glu-1-P), D-glucose 6-phosphate dipotassium salt (Glu-6-P) and fructose 1,6-diphosphate barium salt (Fru-1,6-PP) were purchased from Tokyo Kasei Kogyo (Tokyo, Japan). Adenosine 5'-diphosphate disodium salt (ADP) was purchased from Kohjin (Tokyo, Japan). Boric acid $\left(\mathrm{H}_{3} \mathrm{BO}_{3}\right), \mathrm{L}(+)$ ascorbic acid and ammonium molybdate $\left(\left(\mathrm{NH}_{4}\right)_{6} \mathrm{Mo}_{7}-\right.$ $\mathrm{O}_{24} \cdot 4 \mathrm{H}_{2} \mathrm{O}$ ) were purchased from Wako (Osaka, Japan). Sodium chloride $(\mathrm{NaCl})$, sodium sulfate $\left(\mathrm{Na}_{2} \mathrm{SO}_{4}\right)$, potassium phosphate, dibasic $\left(\mathrm{K}_{2} \mathrm{HPO}_{4}\right)$, sodium hydroxide $(\mathrm{NaOH})$ and sulfuric acid $\left(\mathrm{H}_{2} \mathrm{SO}_{4}\right)$ were purchased from Kanto (Tokyo, Japan). They were all guaranteed reagents and were used without further purification. Organic phosphates were dissolved in a Milli-Q water (Nihon Millipore Kogyo, Yonezawa, Japan) to make $100 \mu \mathrm{M}$ sample solutions. The molybdenum reagent described by Baba et al. ${ }^{1}$ was modified to contain $5.0 \mathrm{M} \mathrm{NaOH}, 0.65 \%(\mathrm{w} / \mathrm{v})$ ammonium molybdate and $1.65 \%(\mathrm{w} / \mathrm{v}) \mathrm{L}(+)$-ascorbic acid. 


\section{Established organic phosphates analyzer system}

A schematic diagram of the organic phosphates analyzer is shown in Fig. 1. A borate buffer (A) was delivered as an eluent at a flow rate of $0.5 \mathrm{ml} \mathrm{min} \mathrm{m}^{-1}$ with a JASCO TRIROTAR-VI pump (Tokyo, Japan). Ten microliters of the sample solution were introduced via a Rheodyne 7125 injector (Cotati, CA, USA) with a $10 \mu \mathrm{l}-$ microsyringe. Separation of the organic phosphates was performed using an Asahipak NH2P-50 column $(4.6 \mathrm{~mm}$ i.d. $\times 250 \mathrm{~mm})(5)$ at either 40 or $50^{\circ} \mathrm{C}$. The absorbance of the effluent was measured at $220 \mathrm{~nm}$ (JASCO UVIDEC-100-VI) (6). The effluent was added with a $4.0 \mathrm{M} \mathrm{H}_{2} \mathrm{SO}_{4}$ solution (B) delivered through an SNK FI-3000 double-plunger pump (Sanuki Industry, Tokyo, Japan) at $0.5 \mathrm{ml} \mathrm{min}$, $^{-1}$ introduced into a hydrolysis coil (PTFE, $0.5 \mathrm{~mm}$ i.d. $\times 30 \mathrm{~m}$ ) in a KWD-2R postcolumn reactor (Kyowa Seimitsu, Tokyo, Japan) (8) and heated at $170^{\circ} \mathrm{C}$ in order to liberate orthophosphate. The resultant orthophosphate was reacted at $120^{\circ} \mathrm{C}$ with a molybdenum reagent $(\mathrm{C})$, which was delivered through the SNK FI-3000 double-plunger pump at $0.5 \mathrm{ml} \mathrm{min}^{-1}$, to form the so-called heteropoly blue complex, and cooled in a $2 \mathrm{~m}$ cooling coil (13). Finally, the absorbance was measured at $830 \mathrm{~nm}$ with a Soma S-3250 spectrophotometer (Soma Optics, Tokyo, Japan) (14). A back-pressure coil $(0.25 \mathrm{~mm}$ i.d. $\times 3.5 \mathrm{~m})(17)$ was set so as to suppress any air bubbling at high temperature,

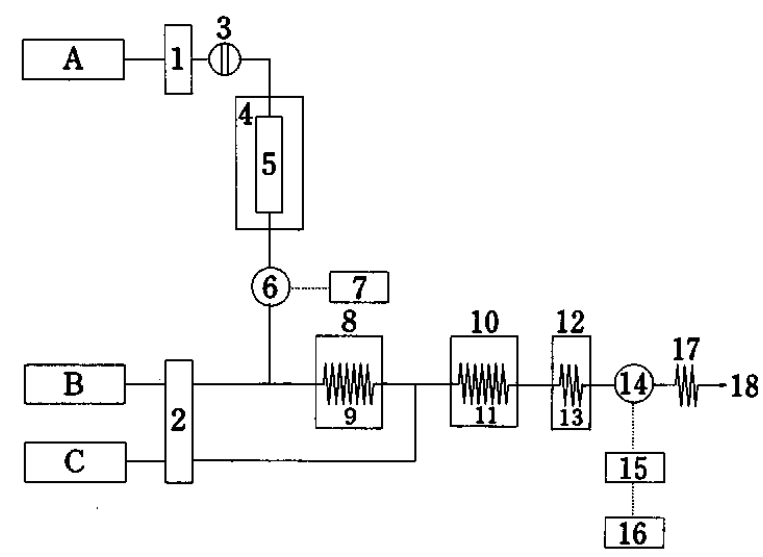

Fig. 1 Schematic diagram of the organic phosphates analyzer. A, eluents; $\mathrm{B}, 4.0 \mathrm{M} \mathrm{H}_{2} \mathrm{SO}_{4}$ solution; $\mathrm{C}$, molybdenum reagent. 1, pump (JASCO TRIROTAR-VI; $0.5 \mathrm{ml} \mathrm{min}^{-1}$ ); 2, pump (SNK FI-3000; $0.5 \mathrm{ml} \mathrm{min}^{-1}$, respectively); 3, injector (Rheodyne 7125); 4, column oven (JASCO TU-300; 40 or $50^{\circ} \mathrm{C}$ ); 5, anion-exchange column (Asahipak NH2P-50; $4.6 \mathrm{~mm}$ i.d. $\times 250 \mathrm{~mm}$ ); 6, spectrophotometer (JASCO UVIDEC-100-VI; $220 \mathrm{~nm}$ ); 7, integrator (JASCO 807-IT); 8, postcolumn reactor (Kyowa Seimitsu KWD-2R; $170^{\circ} \mathrm{C}$ ); 9, hydrolysis coil (PTFE; inner diameter $0.5 \mathrm{~mm}$, outer diameter $1.5 \mathrm{~mm} \times 30 \mathrm{~m}) ; 10$, aluminum block bath $\left(120^{\circ} \mathrm{C}\right)$; 11 , coloration reaction coil $(0.5 \mathrm{~mm}$ i.d. $\times 10 \mathrm{~m}) ; 12$, cooling bath (ice/water); 13 , cooling coil $(0.5 \mathrm{~mm}$ i.d. $\times 2 \mathrm{~m}) ; 14$, spectrophotometer (Soma S-3250; $830 \mathrm{~nm}$ ); 15, signal cleaner (Tomsic SC77); 16, integrator (JASCO 807-IT); 17, backpressure coil $(0.25 \mathrm{~mm}$ i.d. $\times 3.5 \mathrm{~m}) ; 18$, waste. giving an appropriate pressure $\left(\mathrm{ca} .10 \mathrm{~kg} / \mathrm{cm}^{2}\right)$.

\section{Results and Discussion}

\section{Optimization of the separation condition}

The elution conditions for the nucleotides, phosphoamino acids and sugar phosphates chosen as representatives of the organic phosphates were separately examined. Although phosphate buffers have previously been commonly used as the eluent for the anion-exchange chromatography of organic phosphates, they could not be used since they reacted with the postcolumn molybdenum reagent. In this experiment we therefore aimed to find elution conditions for organic phosphates by using borate buffers which showed no reactivity toward the molybdenum reagent.

First, the separation condition of nucleotides (AMP, ADP and ATP) was examined. By using a $50 \mathrm{mM}$ borate buffer containing $300 \mathrm{mM} \mathrm{Na}_{2} \mathrm{SO}_{4}$, the effect of the $\mathrm{pH}$ on the retention of the solutes was examined at pH $9-10$. Judging from the resolultion and shapes of the peaks, $\mathrm{pH} 9.5$ was selected. Next, the concentration of $\mathrm{Na}_{2} \mathrm{SO}_{4}$ to be added to a $50 \mathrm{mM}$ borate buffer ( $\mathrm{pH} 9.5$ ) was examined over the range $50-300 \mathrm{mM} ; 120 \mathrm{mM}$ $\mathrm{Na}_{2} \mathrm{SO}_{4}$ gave the best separation for the nucleotides. Figure 2 shows the HPLC profile of the nucleotides as well as the inorganic phosphate obtained under the optimized condition.

Secondly, the separation condition of the phosphoamino acids (P-Ser, P-Thr and P-Tyr) was examined as in the case of the nucleotides. When $50 \mathrm{mM} \mathrm{Na}_{2} \mathrm{SO}_{4}$ in $50 \mathrm{mM}$ borate buffer ( $\mathrm{pH} \mathrm{8.0)}$ was used as the eluent, a satisfactory resolution was obtained (Fig. 3).

Thirdly, the elution condition was optimized for the resolution of sugar phosphates, such as Glu-1-P, Glu-6-

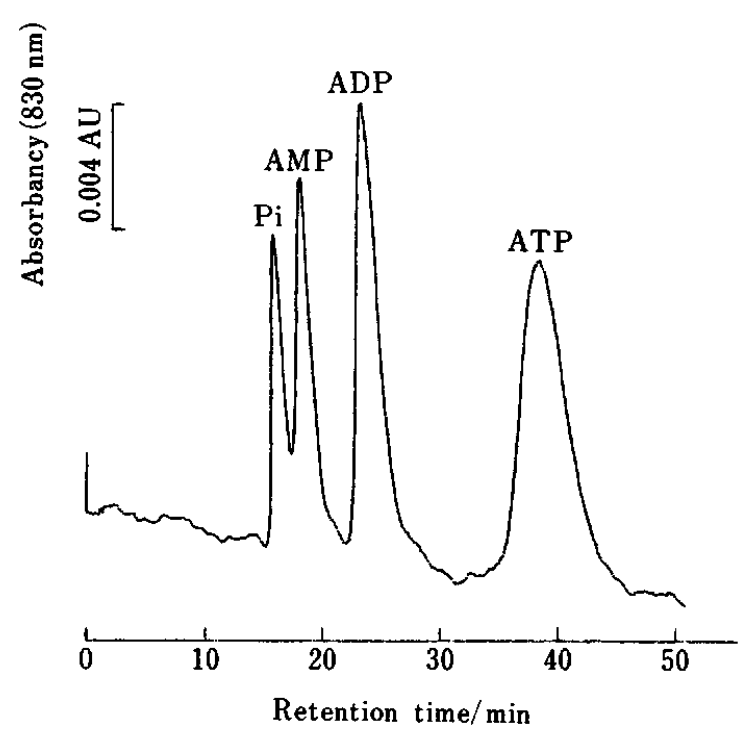

Fig. 2 HPLC profile for nucleotides. Eluent, $120 \mathrm{mM}$ $\mathrm{Na}_{2} \mathrm{SO}_{4}$ in $50 \mathrm{mM}$ borate buffer ( $\mathrm{pH} 9.5$ ); column temperature, $40^{\circ} \mathrm{C}$; injected amount, $1.0 \mathrm{nmol}$ each. 


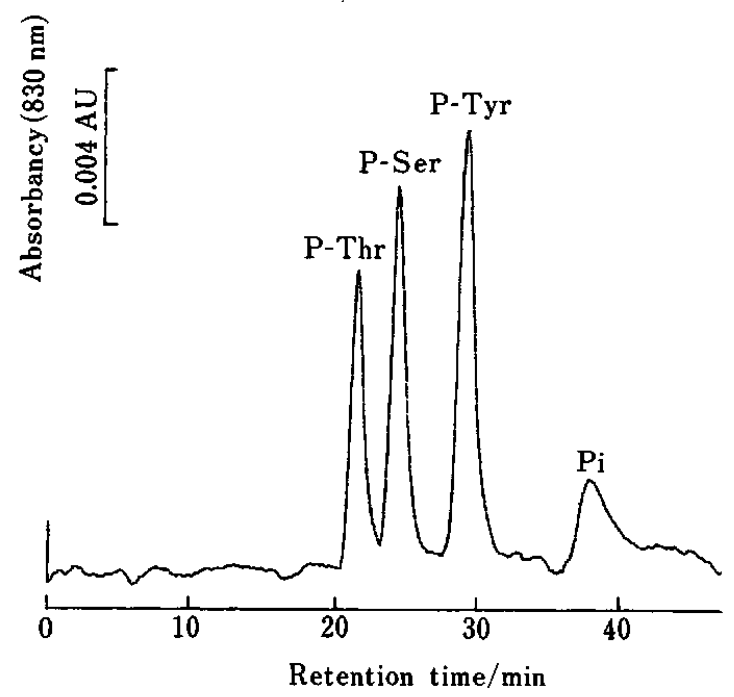

Fig. 3 HPLC profile for phospho-amino acids. Eluent, $50 \mathrm{mM} \mathrm{Na}_{2} \mathrm{SO}_{4}$ in $50 \mathrm{mM}$ borate buffer ( $\mathrm{pH} \mathrm{8.0)}$; column temperature, $40^{\circ} \mathrm{C}$; injected amount, $1.0 \mathrm{nmol}$ each.

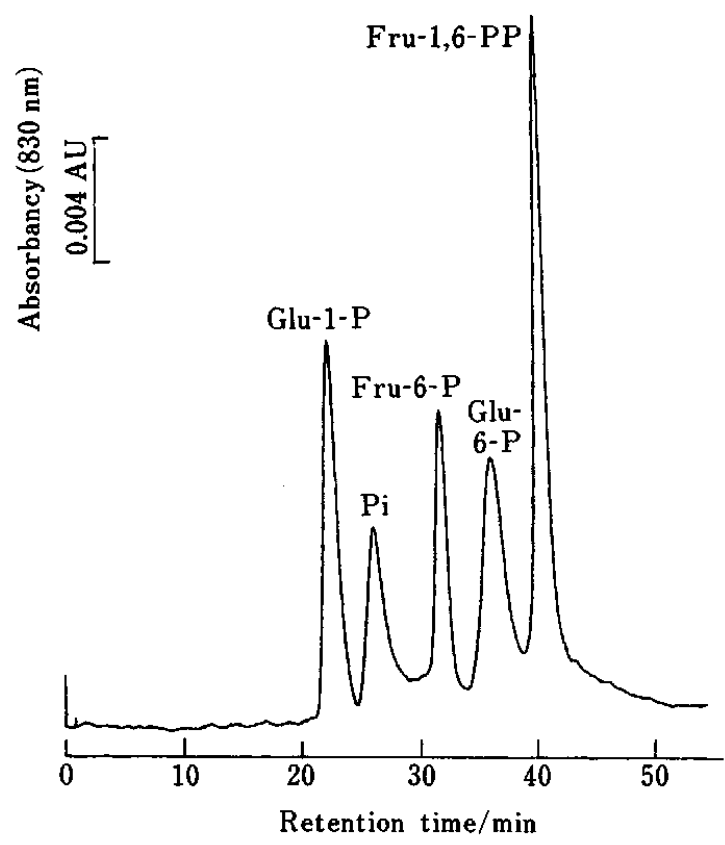

Fig. 4 HPLC profile for sugar phosphates. Column temperature, $50^{\circ} \mathrm{C}$; injected amount, $1.0 \mathrm{nmol}$ each.

P, Fru-6-P and Fru-1,6-PP, which are the main metabolic intermediates in the glycolytic pathway. In this case, all of the isocratic conditions tested gave unsatisfactory results. Therefore, gradient elution was incorporated in the separation of sugar phosphates. The optimized program was isocratic elution with $100 \mathrm{mM} \mathrm{NaCl}$ in $100 \mathrm{mM}$ borate buffer $(\mathrm{pH} 8.5)$ for $5 \mathrm{~min}$, linear gradient elution to $500 \mathrm{mM} \mathrm{NaCl}$ in $100 \mathrm{mM}$ borate buffer (pH 8.5) in $20 \mathrm{~min}$, and then isocratic elution with $500 \mathrm{mM} \mathrm{NaCl}$ in $100 \mathrm{mM}$ borate buffer ( $\mathrm{pH} \mathrm{8.5)} \mathrm{for} 15 \mathrm{~min}$. Figure 4 shows the HPLC profile of the sugar phosphates obtained under the
Table 1 Analytical results for organic phosphates

\begin{tabular}{|c|c|c|}
\hline Compound & $\begin{array}{l}\text { Correlation } \\
\text { coefficient }^{\mathrm{a}}\end{array}$ & R.S.D. ${ }^{b}, \%$ \\
\hline $\mathrm{AMP}^{\mathrm{c}}$ & 0.9941 & \\
\hline $\mathrm{ADP}^{\mathrm{c}}$ & 0.9976 & \\
\hline ATPc & 0.9955 & \\
\hline O-Phospho-DL-serine ${ }^{\mathrm{d}}$ & 0.9938 & \\
\hline O-Phospho-L-threonine ${ }^{\mathrm{d}}$ & 0.9940 & \\
\hline$O$-Phospho-DL-tyrosine ${ }^{d}$ & 0.9972 & \\
\hline Glucose 1-phosphate & 0.9927 & 2.10 \\
\hline D-Glucose 6-phosphate & 0.9953 & 2.05 \\
\hline D-Fructose 6-phosphate & 0.9968 & 1.97 \\
\hline Fructose 1,6-diphosphate & 0.9920 & 2.56 \\
\hline
\end{tabular}

a. $n=2$. b. $n=8$. c. HPLC condition was the same as in Fig. 2. d. HPLC condition was the same as in Fig. 3. e. HPLC condition was the same as in Fig. 4.

optimized elution condition.

\section{Reproducibility and calibration curve}

As shown in Table 1 , when $100 \mu \mathrm{M}$ each of sugar phosphate was repeatedly determined, the relative standard deviation was between 1.97 and $2.56 \%(n=8)$. The calibration curves for the organic phosphates showed good linearity (correlation coefficient $\geq 0.992$ ). This method permitted the determination of organic phosphates in the $20-500 \mu \mathrm{M}$ range (injection volume, $10 \mu \mathrm{M})$.

The organic phosphates analyzer presented here seems to be the first tool which enables a sensitive and selective determination of various types of organic phosphates. The analyzer is expected to be widely applied to various biomedical purposes, including the determination of organic phosphates and assays of phosphatases and kinases.

\section{References}

1. Y. Baba, Y. Yamamoto, N. Yoza and S. Ohashi, Bunseki Kagaku, 34, 692 (1985).

2. Y. Baba, M. Tsuhako and N. Yoza, J. Chromatogr., 507, 103 (1990).

3. Y. Ikeguchi, H. Nakamura and T. Nakajima, Anal. Sci., 9, 397 (1993).

4. C. House, R. E. Wettenhall and B. E. Kemp, J. Biol. Chem., 262, 772 (1987).

5. R. Toomik, P. Ekman and L. Engstrom, Anal. Biochem., 204, 311 (1992).

6. S. Sullivan and T.-W. Wong, Anal. Biochem., 197, 65 (1991).

7. R. J. A. Budde, J. S. McMurray and D. A. Tinker, Anal. Biochem., 200, 347 (1992).

8. M. Kawahara, H. Nakamura and T. Nakajima, Anal. Sci., 5, 763 (1989).

9. H. Matsuda, H. Nakamura and T. Nakajima, Anal. Sci., 6, 911 (1991).

(Received July 14, 1993)

(Accepted August 18, 1993) 